\title{
Oil-water flow regimes in 4-mm borosilicate glass and fluorinated ethylene propylene
} channels: Effects of wall wettability

\author{
G.A. Riley ${ }^{\mathrm{a}}$, K.K Bultongez ${ }^{\mathrm{a}}$, M.M Derby ${ }^{\mathrm{a},{ }^{*}}$

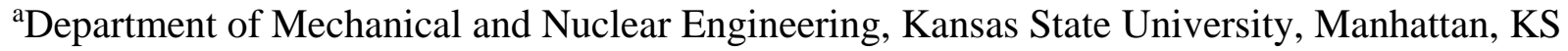 \\ 66506 USA \\ *corresponding author: derbym@ksu.edu, 1701B Platt St., Manhattan, KS 66506, USA, \\ Tel: 785-532-2606, Fax: 785-532-7057
}

\section{Abstract:}

Formation water, found in oil deposits, is highly corrosive. By utilizing flow phenomena and surface tension forces in smaller channels (e.g., Eötvös number less than one), these fluids can be separated, thus altering corrosion and the pressure required for transport. This research investigates the effects of wall wettability on oil-water flow regimes and pressure drops. Oil-water flows were studied in 3.5-mm hydrophilic borosilicate glass and 4.0-mm hydrophobic fluorinated ethylene propylene (FEP) channels using Parol 100 mineral oil (i.e., density of $840 \mathrm{~kg} / \mathrm{m}^{3}$ and viscosity of $0.0208 \mathrm{~Pa} \cdot \mathrm{s}$ ) and tap water (i.e., $997 \mathrm{~kg} / \mathrm{m}^{3}$ and a viscosity of $0.001 \mathrm{~Pa} \cdot \mathrm{s}$ ). For these oil-water combinations, glass was water wetting (i.e., contact angle of $67^{\circ}$ for a water droplet submerged in oil on glass) and FEP was water repelling (i.e., contact angle of $93^{\circ}$ for a water droplet submerged in oil on FEP) under static conditions. Flow regimes and pressure drops were recorded for a range of oil superficial velocities [i.e., $0.31-3.7 \mathrm{~m} / \mathrm{s}$ (glass) and 0.23-2.7 m/s (FEP)] and water superficial velocities [i.e., $0.080 \mathrm{~m} / \mathrm{s}-5.5 \mathrm{~m} / \mathrm{s}$ (glass) and 0.060-5.5 m/s (FEP)]. Stratified, intermittent, annular, and dispersed flow regimes were observed in both tubes. Additional inverted and dual flow regimes were observed in the hydrophobic FEP; oil wetted the wall in inverted flows, and flow regimes occurred inside of another flow regime in dual flows (e.g., 
inverted-annular intermittent). The modified Weber number indicated whether the walls were wetted by oil, mixed oil and water, or water. Pressure drops were found to be correlated to the flow regime with increased pressure drops observed when oil fully or partially wetted the wall.

28 Keywords: multiphase flow; fluid dynamics; oil-water interface; capillarity

\section{GRAPHICAL ABSTRACT}

Annular and Intermittent Flows Inverted Flows Dual Flows

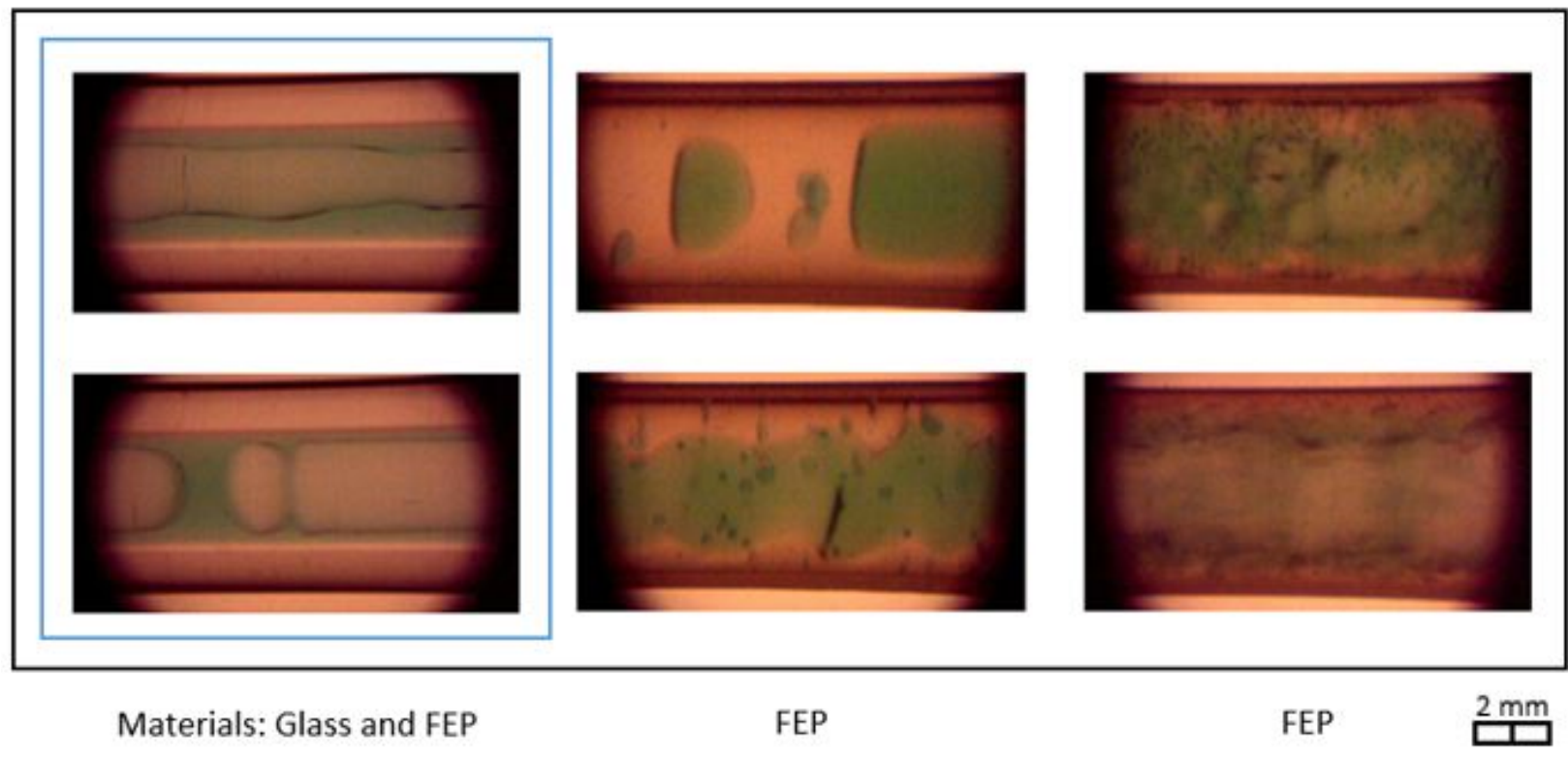

The water has been dyed green for contrast and the oil appears clear.

\section{HIGHLIGHTS}

- Investigated oil-water flows in hydrophilic and hydrophobic 4-mm channels

- Stratified, intermittent, annular, and dispersed flow regimes in both channels

- Inverted (i.e., oil wetting) flow regimes observed in the hydrophobic channel

- $\quad$ Pressure drops depended on flow regimes, tube material, and wetting fluid

\section{INTRODUCTION}

Oil-water flows are of great interest to industry, including water-lubricated transport (i.e., annular flow) of heavy crude [1], reducing corrosion due to water wetting the pipe wall [2], and 39 separating oil-water mixtures [3]. However, there are competing priorities. Water wetting, or 
40 hydrophilic/oleophobic walls, are desirable for reducing pressure drops [4], but the presence of 41 water at the pipe wall accelerates corrosion [2], and thus hydrophobic/oleophilic walls are 42 desirable for reducing corrosion. Oil-water pressure drops and corrosion rates rely heavily on the 43 resulting oil-water flow regime. Different flow regimes appear in mini-channels (e.g., $200 \mu \mathrm{m}<$ $44 \quad D_{h}<3 \mathrm{~mm}$ [5]) compared to conventional-size channels (e.g., $D_{h}>3 \mathrm{~mm}$ [5]) due to the relative 45 importance of surface tension to gravity forces in smaller channels [6]. Flow regime maps 46 developed for air-water flows [7, 8], and liquid-vapor flows during condensation [9, 10] and 47 boiling $[11,12]$ do not directly apply to oil-water flows due to comparable oil-water densities and 48 large oil-water viscosity ratios [6, 13]. Additionally, wall wettability-i.e., whether oil or water is 49 in contact with the wall—affects flow regimes and is therefore an important research topic for oil 50 transport and reducing corrosion. For glass or stainless steel mini-channels, common oil-water flow regimes observed in

52 mini-channels include intermittent (e.g., slug/plug flow), annular (e.g., water at the wall and oil at 53 the core), and dispersed flows (e.g., oil-in-water or water-in-oil) [3, 4, 6, 14, 15]. As pipe diameters 54 increase, gravitational effects are more apparent in forming stratified flows (e.g., water in contact 55 with the bottom of the tube and oil in contact with the upper tube wall) [16-18]. There is an interest 56 in exploring a range of materials to alter the wall wetting fluid. da Silva [19] investigated contact 57 angles of PVC; glass; and stainless, enameled, and galvanized steels for water-lubricated pipeline 58 transport. Glass surfaces had less oil wetting than steel. Oxidizing the materials created hydrophilic 59 rather than oleophilic walls and they observed that both the surface properties and oil composition 60 affected contact angles. Arney et al. [20] studied oil-water flows in 2.43- to 2.65-cm pipes coated 61 with portland cement to make the walls oleophobic and hydrophilic; the cement coating reduced 62 fouling during lengthy tests. 
A combination of wall materials, oil composition, and flow conditions may affect whether

64 oil or water wets the tube wall [2, 4, 18, 21-24]. For certain combinations, inverted annular flows occur in which oil is fully or partially in contact with the tube wall. The core flow can be all water

66 or a mixture of oil and water. This inverted annular flow condition, combined with oil-selective

67 membranes, may be used to separate oil from formation water after the wellhead. Andreini et al.

68 [4] observed dispersed, annular, and intermittent flows in 3.1-mm and 6-mm mini-channels.

69 However, at low velocities (i.e., water superficial velocities divided by oil superficial velocities <

$70 \quad 0.2-0.3$ ) in the 6-mm tube, they observed inverted annular flows in which oil wetted the wall and

71 oil flowed in the core.

Oil wetting and inverted flows have been observed in conventional-size tubes, particularly 73 at low superficial velocities. Cai et al. [2] studied wetting phenomena in a 0.1-m-diameter, 14-m-

74 long stainless steel pipe. Due to the large diameter of the pipe, wetting was primarily a function of 75 flow regime, with oil wetting at low cuts (i.e., $<10 \%$ ), water wetting at higher water cuts (i.e., $76>15 \%$ ) and low total superficial velocities (i.e., $<1 \mathrm{~m} / \mathrm{s}$ ), and intermittent wetting (i.e., alternating 77 water/oil wetting) at conditions in between. Ismail et al. [21] studied pressure drops and flow 78 regimes of Malaysian light waxy crude and synthetic formation water in a 5.08-cm tube. Oil was 79 in contact with the acrylic tube wall at low flow rates and over a range of water cuts. The authors 80 noted that the multi-parameter composition of the Malaysian light waxy crude and oil-wetting 81 acrylic surface likely contributed to this behavior. Wang et al. [22] studied crude oil-water flow 82 regimes and pressure drops in a $25.4-\mathrm{mm}$, stainless steel tube. The study observed flow patterns 83 that were combinations of water-in-oil emulsions with stratified, intermittent, annular, and 84 dispersed flow regimes. In the oil-dominated regimes found (e.g., at water fractions $<50 \%$ ), the 85 authors observed some water-in-oil dispersed flows in which oil partially wetted the tube wall. The 
review by $\mathrm{Xu}$ [23] highlighted the phase inversion point, a sudden switch between oil-in-water

87 dispersions to water-in-oil dispersions and vice versa and noted in linkage between wall-wetting fluid and corrosion. These phase inversions can also affect pressure drops [25].

Capillary, or surface tension forces, are of primary interest as diameter decreases. Tsaoulidis et al. [26] investigated ionic fluid-water flows in glass, FEP and Tefzel with tube diameters of 200 $\mu \mathrm{m}, 220 \mu \mathrm{m}, 270 \mu \mathrm{m}$ respectively. Wettability was an important factor that affected flow regimes in glass (i.e., contact angle of water-in-air of $55^{\circ}$ ) and Teflon (i.e., contact angles of water-in-air of $102^{\circ}$ ) tubes. The authors observed that flows in the glass tube were highly affected by the fluid that first wetted the channel. In all flow regimes, water was the continuous phase and in full contact with the glass tube walls. Plug and intermittent flows were primarily observed in glass tubes, while annular flow was encountered in the Teflon tubes, with water flowing in the core, plug flow and drop flow, with water being the encapsulated liquid. Brauner et al. elaborated on this phenomena occurring in the hydrophobic tubes and named it inverted annular flow [27]. At the lower diameter range of mini-channels, oil-water flow regimes depend on whether oil or water first fills the channel, and stratified flows were not observed due to the increased importance of surface tension over gravity [28, 29]. At even smaller size micro-scales, capillary forces governed imbibition in fabricated, pore-scale geometries [30, 31].

Few studies have examined the impacts of wall materials and flow conditions on flow regimes and wall wetting for mini-channel oil-water flows. The research objectives of this work are to investigate oil-water flow regimes in 3.5- and 4.0-mm glass and fluorinated ethylene propylene (FEP) tubes. For these oil-water combinations, glass is water wetting and FEP is oil wetting under static conditions. Additionally, both channels have an Eötvös number below one, selected because surface tension forces between the fluids will dominate over gravitaional forces; 
109 the Ë̈ numbers in the glass and FEP are 0.4 and 0.6, respectively. The focus of this research is to

110 determine fundamental flow regimes in glass and FEP tubes in order to design systems to separate

111 oil and water after the wellhead; future work will need to consider higher temperatures and

112 pressures.

\section{2. MATERIALS AND METHODS}

\section{$114 \quad 2.1$ Tube Materials and Fluid Properties}

Oil-water flows were studied in 3.5-mm borosilicate glass and 4.0-mm fluorinated ethylene propylene (FEP) tubes. The borosilicate glass is hydrophilic (i.e., water contact angle of

$11718^{\circ}$ ), whereas the FEP is hydrophobic (i.e., contact angle of $91^{\circ}$ ) under static conditions between 118 water and air; goniometer images with water and air are shown in Figure 1a. Both materials are 119 oleophilic with contacts angles of $36^{\circ}$ and $44^{\circ}$ on glass and FEP respectively as shown in Figure

120 1b. Experiments were conducted using tap water (e.g., $\rho=997 \mathrm{~kg} / \mathrm{m}^{3}, \mu=0.001 \mathrm{~Pa} \cdot \mathrm{s}$ )—dyed green 121 for visualization —and Parol $100^{\mathrm{TM}}$ mineral oil (e.g., $\left.\rho=840 \mathrm{~kg} / \mathrm{m}^{3}, \mu=0.0208 \mathrm{~Pa} \cdot \mathrm{s}\right)$. Campus tap 122 water properties were reported by Schmitz [32]. The electrical conductivity was $0.2 \mathrm{dS} / \mathrm{m}, \mathrm{pH}$ 123 was 8.7, and the concentrations of the following chemicals were reported: $\mathrm{S}, \mathrm{K}, \mathrm{Na}, \mathrm{Mg}, \mathrm{Ca}$, 124 Chloride, NO3-N and NH4-N were 19, 8, 31, 15, 14, 58, 0, and $1 \mathrm{mg} / \mathrm{L}$ respectively. Interfacial 125 tensions between Parol 100 and tap water were $38.8 \mathrm{mN} / \mathrm{m}$ and were measured using the pendant 126 drop method conducted by Augustine Scientific [33]. The contact angle of water submerged in 127 oil was also measured by Augustine Scientific, resulting in water-oil contact angles of $67^{\circ}$ on 128 glass and $93^{\circ}$ on FEP, as shown in Figure 2a and 2b, respectively. For this oil-water combination, 129 glass is hydrophilic and FEP is hydrophobic. 
(a)

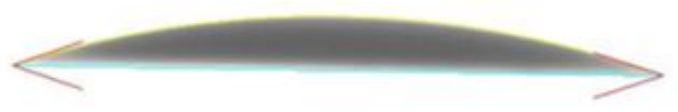

(c)

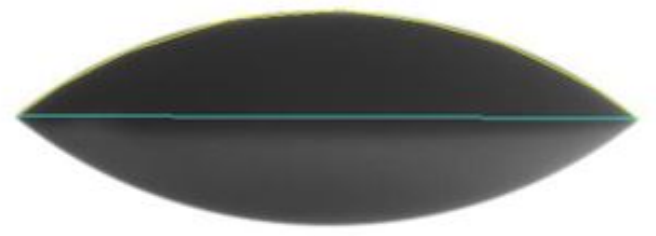

(a)

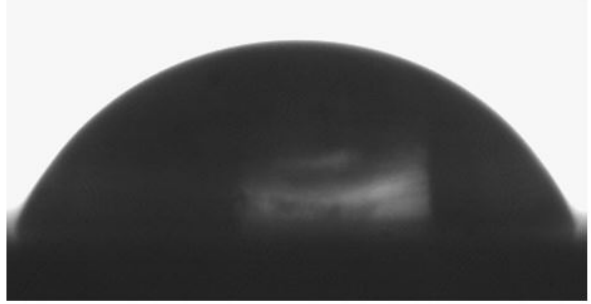

133

\subsection{Experimental Apparatus and Test Section}

(b)

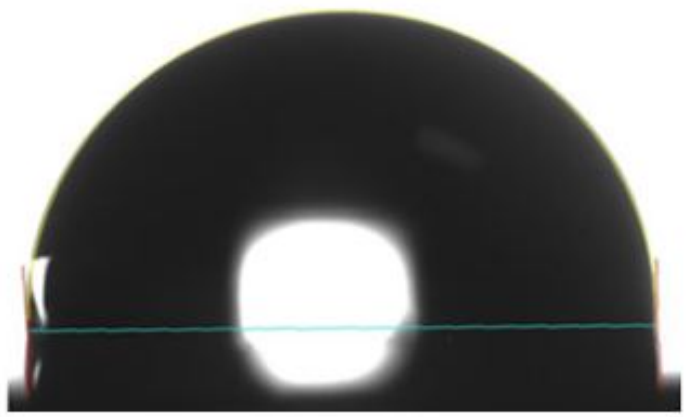

(d)

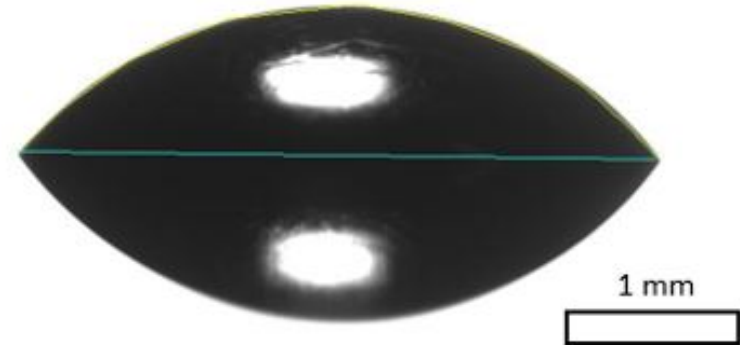

Figure 1: Contact angles of water surrounded by air for (a) water on glass, (b) water on FEP, (c) oil on glass, and (d) oil on FEP.

(b)

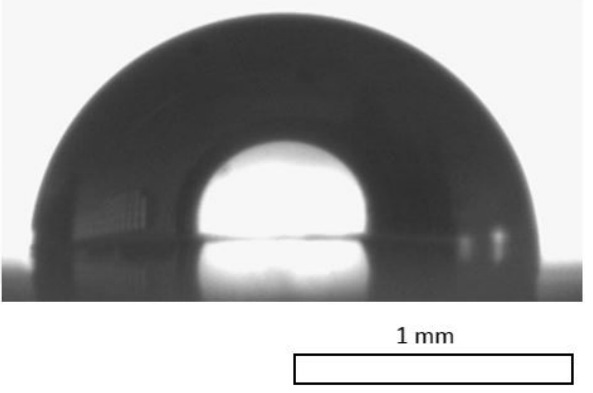

Figure 2: Contact angles of water submerged in oil for (a) glass and (b) FEP

The experimental apparatus, shown in Figure 3, was an adiabatic, closed-loop system. Oil and water were stored in a 30-galUS tank and were transported independently by two pumps (GCM25.PS5S.E, Micropump) controlled via variable frequency drives. Water was sourced from the bottom of the tank and oil from the top; the measured densities confirmed that the two fluids were 
141 not mixed. Each fluid passed through its respective Coriolis flowmeter (CMFS015M, Micro

142 Motion) where the fluid's mass flow rate, density, and temperature were measured before mixing

143 in a y-junction. The oil-water mixture then flowed through a 680-mm-long channel, which allowed

144 the flow to fully develop before entering the test section shown in Figure 4. The pressure

145 differential across the test section was measured via a 50-psi pressure transducer (Setra) with

$146 \pm 0.25 \%$ full scale accuracy. To measure the pressure drop, holes were drilled into the FEP channel

147 at the T-junctions (Figure 4). For the glass channel, custom-made inserts were fit inside the T-

148 junction and allowed for the pressure measurements to be recorded. Both test section lengths were

$149387 \mathrm{~mm}$. The two-phase flow entered the tank and the oil-water flow was separated using gravity.

150 Flow regimes were visualized through the channel wall of the test section using a high-speed

151 camera (Fastec IL5) with a microscope (Leica S6 D).

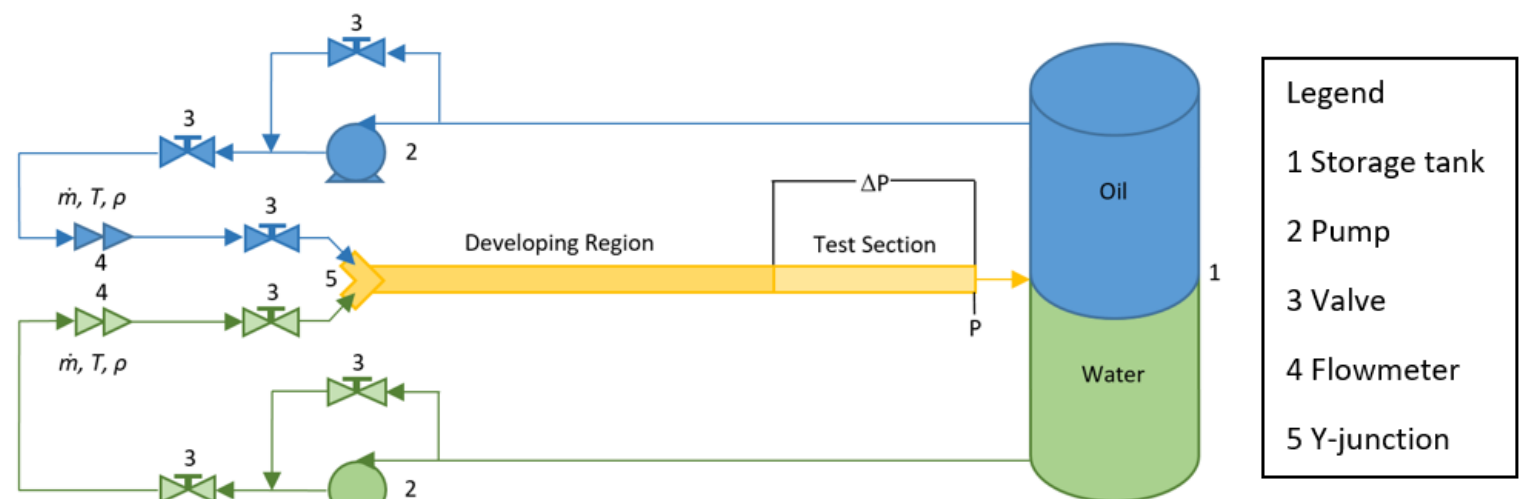




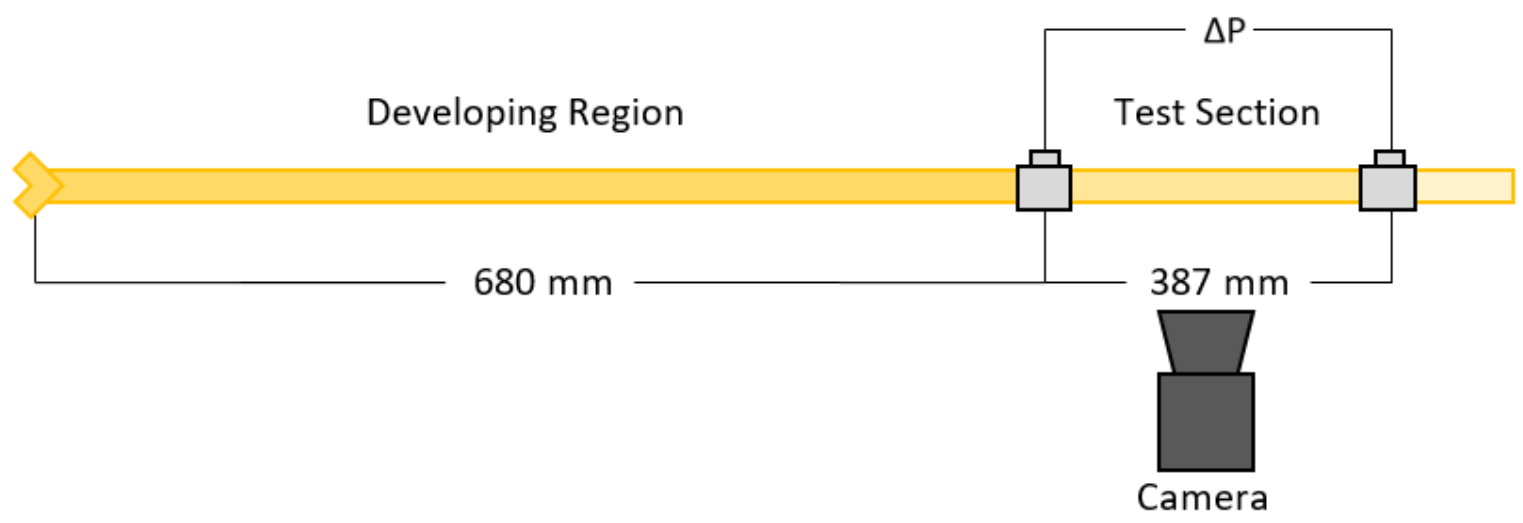

Figure 4: Test section for pressure drop measurement and flow visualization.

\subsection{Experimental Procedures}

The desired flow conditions were reached by independently controlling oil and water mass

159 flow rates, and data are presented in terms of the superficial velocities, $j$, and the water input ratio,

$160 \varepsilon$. The superficial velocity is the mass flow rate of the fluid, $\dot{m}$, divided by its density, $\rho$, and the 161 total cross-sectional area of the channel, $A$,

$$
j_{w}=\frac{\dot{m}_{w}}{\rho_{w} A} \quad \text { (1) } \quad j_{o}=\frac{\dot{m}_{o}}{\rho_{o} A}
$$

162 where subscripts $w$ and $o$ correspond to water and oil, respectively. The water input ratio is the 163 water superficial velocity divided by the combined superficial velocity of both the oil and water,

$$
\varepsilon=\frac{j_{w}}{j_{o}+j_{w}}=\frac{\dot{m}_{w}}{\frac{\rho_{W} \dot{m}_{o}}{\rho_{o}}+\dot{m}_{w}}
$$

164 and, therefore, the water-oil density ratio and relative mass flow rates impact the water input ratio.

For two-phase experiments, the experimental data were collected using the following 166 procedure:

167 1. An oil mass flow rate was selected and water input ratios were specified in increments of 0.1. 
2. The water mass flow rates required for the water input ratio range were calculated using equation

169

170

171

172

173

174

175

176

177

178

179

180

181

182

183

184

185

186

187

188

189

190

(3).

3. Water was introduced into the system and set approximately to the lowest flow rate being tested.

4. Oil was introduced to the system and both oil and water flow rates were adjusted until desired values were reached with minimal fluctuations.

5. After steady state occurred, pressure, temperature, mass flow rate, and density measurements were recorded. Still images and video of flow regime were taken.

6. Water flow rate was increased to achieve next lowest water input ratio.

7. Steps 5 and 6 were repeated until data for all water input ratios has been collected.

8. Return to Step 1 with new oil mass flow rate and repeat the process.

Data were collected and analyzed for a given oil flow rate at all water flow rates achievable in the experimental apparatus. In addition to the previously stated procedure, two to three data points per oil flow rate were repeated for verification of flow regime and pressure drop.

\section{RESULTS AND DISCUSSION}

\subsection{Observed Flow Regimes in the Glass Tube}

Flow regimes observed in hydrophilic millimeter tubes, such as borosilicate glass, can be classified as stratified, intermittent, annular, and dispersed [3, 4, 15] (Figure 5). In stratified flows (Figure 5a), the oil and water are separated by gravity and the less dense fluid flows above the denser fluid. Stratified flow is an example of mixed wetting (i.e., wall wetted by both oil and water) and occupied a small fraction of flow conditions due to the low Eötvös number of these channels. Intermittent flows are similar to annular flows in which a water annulus surrounds an oil core and is periodically separated by periods of water flow only (Figure 5b). For annular flows in these 
191 channels, water completely wetted the surface and an oil core flows through the water annulus

192 (Figure 5c). In dispersed flows, the oil and water are mixed such that no clear boundary between

193 the two fluids exists (Figure 5d). These flow regimes can be further classified based on the 194 presence of waves at the oil-water interface and fluid wetting the tube wall; water wetted the wall 195 in annular, intermittent, and dispersed flows.

(a)

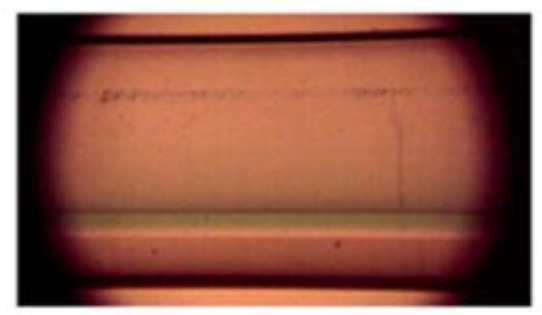

(b)

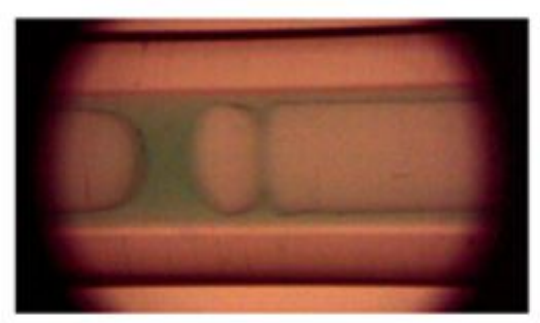

196

\subsection{Observed Flow Regimes in the FEP Tube}

(c)

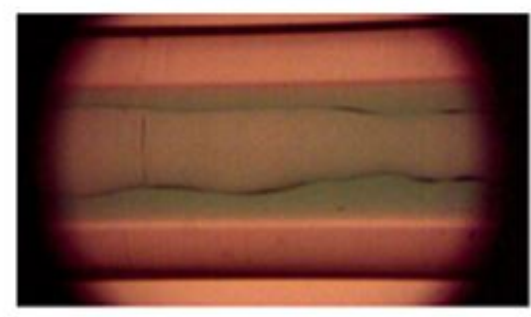

(d)

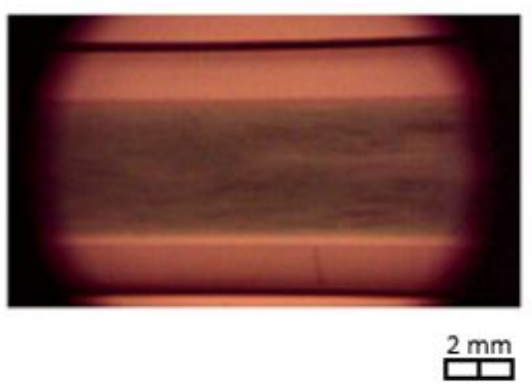

Figure 5: Hydrophilic flow regimes-(a) stratified, (b) intermittent, (c) annular, and (d) dispersed.

Stratified, intermittent, annual, and dispersed flows were observed in the 4.0-mm FEP tube (Figure 6a, j, k, l) in addition to inverted or dual flow regimes [2, 4, 21, 22]. An additional eight distinct flow regimes were identified in the FEP mini-channel that are described as being either inverted (e.g., with oil wetting the wall and a water core flowing through it) [25, 34], flow with a rivulet [35], or a dual flow in which a flow regime occurring inside of another flow regime (e.g., 
206 in an inverted-annular intermittent flow oil is wetting the wall and forms and annulus through

207 which a water core flows with an intermittent oil core inside the water core).

208 Due to the hydrophobicity of FEP, oil wets the tube wall in inverted flows. In Figure 6, all 209 twelve flow regimes observed in the FEP are shown. Inverted flows are notated as "inverted-flow", 210 dual flows are listed as "inner flow-outer flow", and flows with a rivulet are described as "flow 211 with rivulet”. In inverted-intermittent (Figure 6b), inverted-annular flows (Figure 6c), and 212 inverted-dispersed (Figure 6d), oil wets the tube wall and an intermittent or continuous water core 213 flow is formed. Inverted-intermittent intermittent flow consists of an oil-wetting annulus through 214 which a core of water will periodically flow through with an oil core intermittently flowing through 215 the water core (Figure 6e). Inverted-annular annular and inverted-annular intermittent flows occur 216 when the water core inside of the wetting oil annulus has either a continuous or intermittent core 217 of oil flowing through it (Figure $6 \mathrm{f}$ and $\mathrm{g}$ ). Annular with oil rivulet and intermittent with oil rivulet 218 are similar to common annular and intermittent flow regimes but have a rivulet of oil that flows 219 along the top of the channel, wetting a portion of the wall (Figure 6h-i). 
(a)

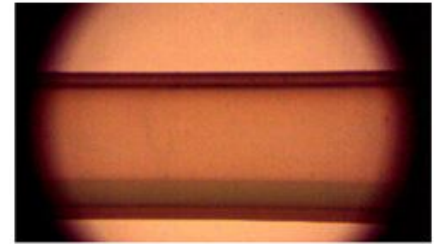

(b)

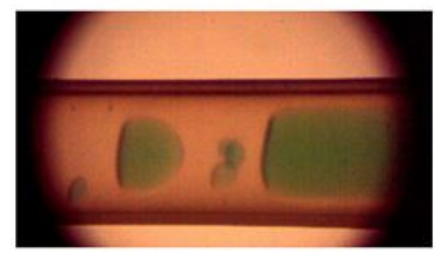

(c)

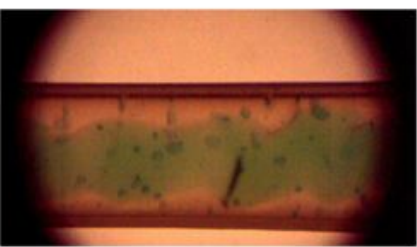

(d)

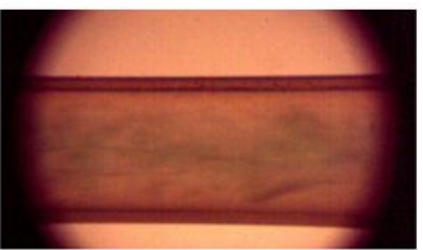

(e)

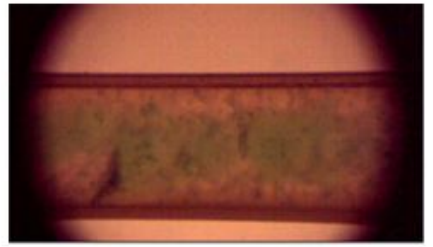

(f)

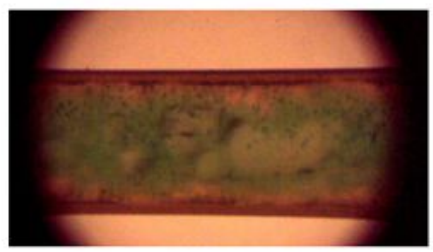

(g)

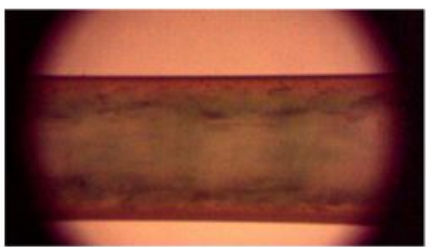

(h)

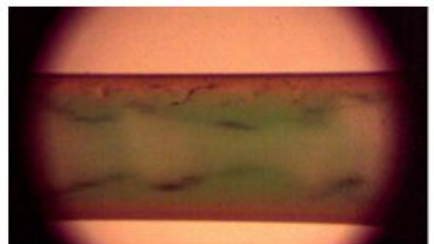

(i)

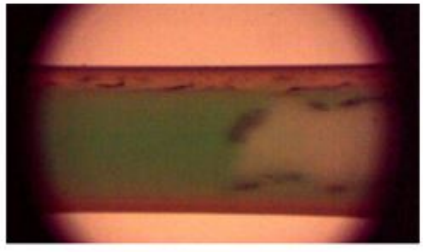

(j)

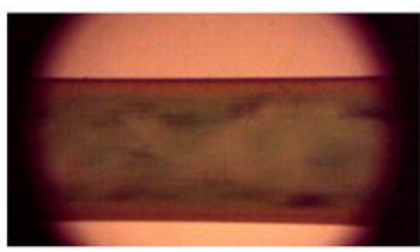

(k)

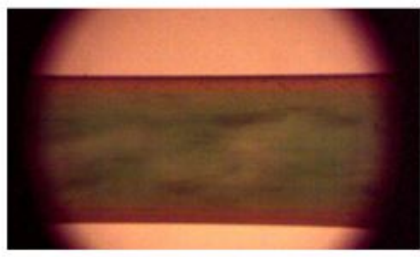

(I)

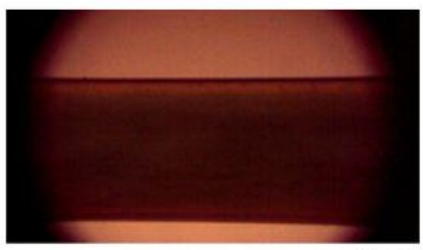

Figure 6: Hydrophobic flow regimes-(a) stratified, (b) inverted-intermittent, (c) invertedannular, $(d)$ inverted-dispersed, $(e)$ inverted-intermittent intermittent, $(f)$ inverted-annular intermittent, (g) inverted-annular annular, (h) annular with oil rivulet, (i) intermittent with oil rivulet, (j) annular, (k) intermittent, and (l) dispersed.

\subsection{Flow Regime Maps}

Flow regimes are mapped for the glass (Figure 7) and FEP (Figure 8) tubes. In both tube

227 materials, stratified flows occurred when the total superficial velocity was low (i.e., $j_{o}<1.28 \mathrm{~m} / \mathrm{s}$, $j_{w}<0.20 \mathrm{~m} / \mathrm{s}$ ). In the glass mini-channel, annular flow was the dominant flow regime when the oil

229 flow rate was greater than the water flow rate (i.e., $0.31 \mathrm{~m} / \mathrm{s}<j_{o}<3.7 \mathrm{~m} / \mathrm{s}, 0.26 \mathrm{~m} / \mathrm{s}<j_{w}<2.5 \mathrm{~m} / \mathrm{s}$ ); 230 conversely, intermittent flows dominated when the water flow rate was higher than that of the oil 231 (i.e., $0.31 \mathrm{~m} / \mathrm{s}<j_{o}<3.7 \mathrm{~m} / \mathrm{s}, 0.48 \mathrm{~m} / \mathrm{s}<j_{w}<3.7 \mathrm{~m} / \mathrm{s}$ ). For the largest water flow rates (i.e., $3.7 \mathrm{~m} / \mathrm{s}<j_{w}$ ), 
232 dispersed flows were observed. These flow regimes are commensurate with those observed in 233 previous mini-channel oil-water flow research [3, 28, 36]; macro-scale channels exhibit stronger 234 gravity impacts and stratified flow is typically the dominant flow regime [6, 37], whereas surface 235 tension is a key driver in micro-channel flow regimes [30, 31].

236 For the FEP mini-channel, as the superficial velocity increased (i.e., $j_{\text {tot }}>0.38 \mathrm{~m} / \mathrm{s}$ ), the 237 flow regimes become inverted, oil wetting (Figure 8). As the oil flow rate progressed from lowest 238 (i.e., $j_{o}=0.23 \mathrm{~m} / \mathrm{s}$ ) to highest (i.e., $j_{o}=2.7 \mathrm{~m} / \mathrm{s}$ ) in the inverted region, the flow regimes trended from 239 inverted-annular to inverted-intermittent to inverted-dispersed. Further increasing the water flow 240 rate (i.e., $0.33 \mathrm{~m} / \mathrm{s}<j_{w}<1.2 \mathrm{~m} / \mathrm{s}$ ) lead to the dual flows, which, with an increasing oil flow rate, tend 241 from inverted-annular intermittent to inverted-annular annular. Inverted-intermittent intermittent 242 flows occurred in the region between inverted-intermittent and inverted-annular intermittent flows. 243 After the water flow rate was further increased (i.e., $1.4 \mathrm{~m} / \mathrm{s}<j_{w}<2.1 \mathrm{~m} / \mathrm{s}$ ), the flow regimes 244 developed oil rivulets in conjunction with either an intermittent flow, mixed wetting, for lower oil 245 flow rates (i.e., $j_{o}=0.91 \mathrm{~m} / \mathrm{s}$ ), or an annular flow, for higher oil flow rates (i.e., $1.4 \mathrm{~m} / \mathrm{s}<j_{o}<2.7 \mathrm{~m} / \mathrm{s}$ ). 246 The oil rivulets disappeared as the water flow rate was further increased (i.e., $1.8 \mathrm{~m} / \mathrm{s}<\mathrm{j}_{w}<3.4 \mathrm{~m} / \mathrm{s}$ ) 247 and the flow regimes were either intermittent or annular, water wetting, depending on the oil flow 248 rate. As with the glass, for the highest total superficial velocities, the flow regime was dispersed. 


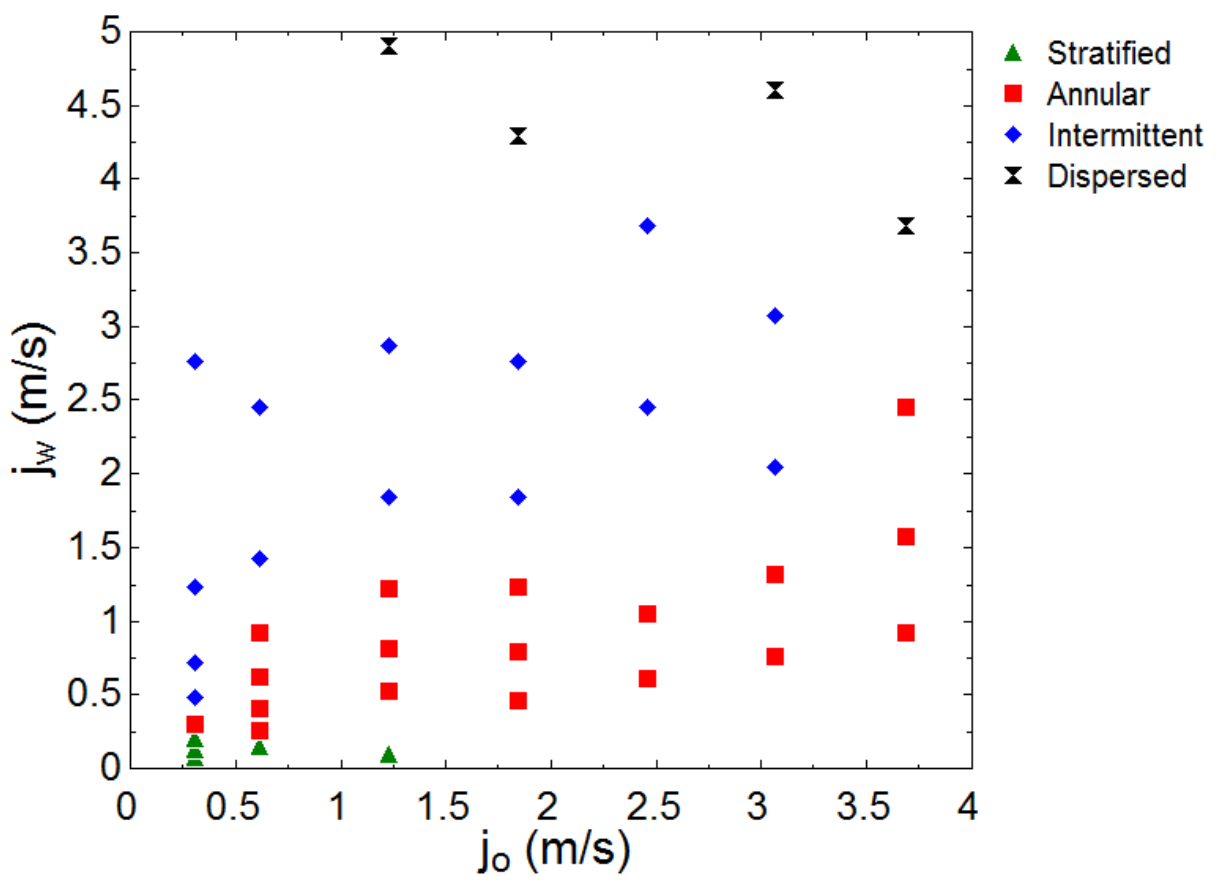

251 Figure 7: Flow regimes in the glass tube-mixed oil-water wetting in stratified flows and water wall wetting in annular, intermittent, and dispersed flows.

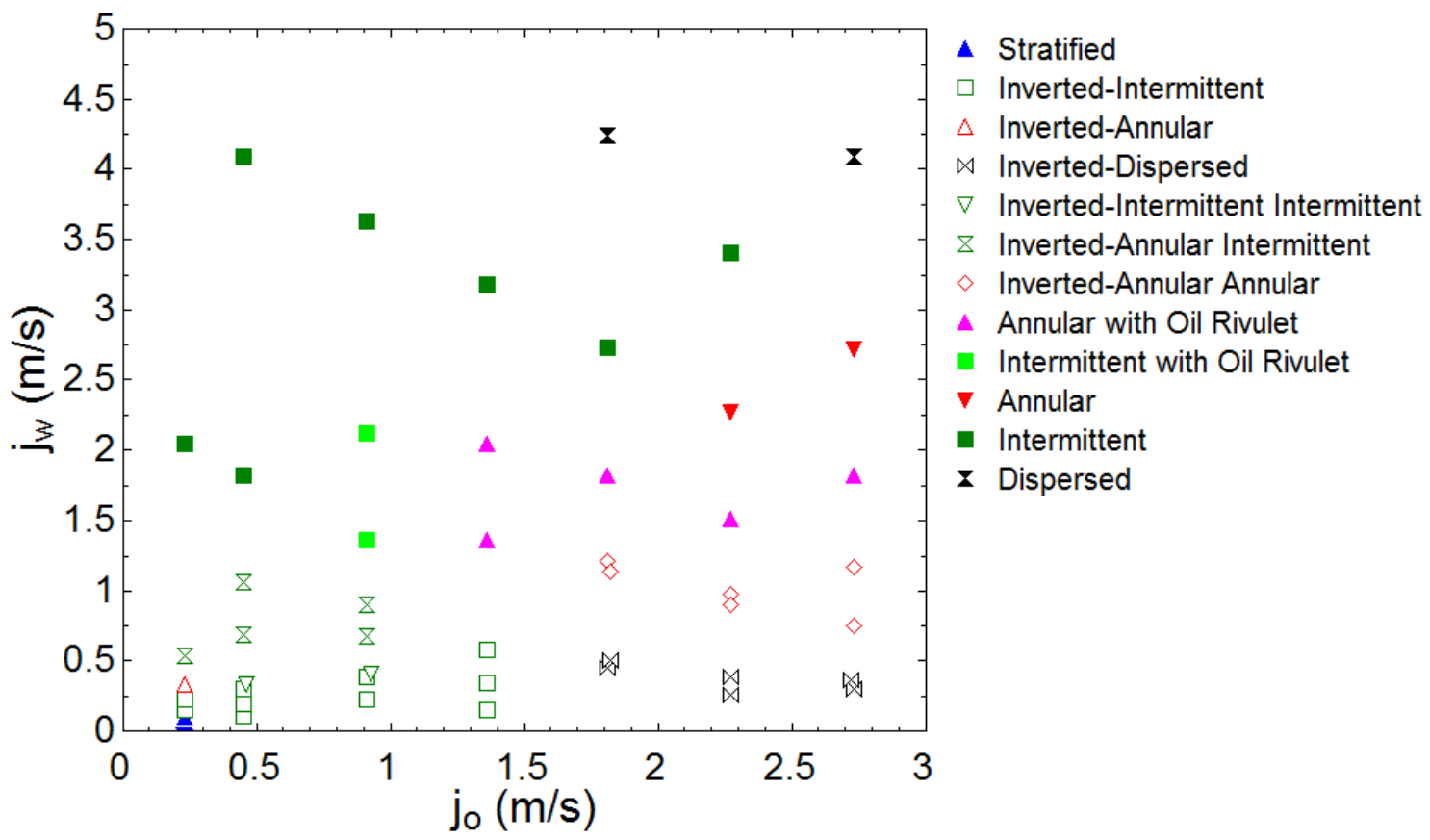

Figure 8: Flow regimes in the FEP tube. 
To better understand the presence of oil wetted flow regimes (e.g., inverted-intermittent),

257 an analysis using the modified Weber number $\left(W e^{*}\right)$ was conducted. $W e^{*}$ is the ratio between

258 inertial and surface tension forces between fluids, which Kim and Mudawar [38, 39] used to

259 determine transition regions between flow regimes in two phase condensers. For the purpose of 260 adapting these equations to liquid-liquid flows, oil was approximated as the liquid, water as the 261 gas, and the quality as $j_{w} / j_{t o t}$,

$$
\begin{gathered}
W e^{*}=2.45 \frac{R e_{w}^{0.64}}{S u_{w}^{0.3}\left(1+1.09 X_{t t}^{0.039}\right)^{0.4}} \text { for } R e_{o} \leq 1250 \\
W e^{*}=0.85 \frac{R e_{w}^{0.79} X_{t t}^{0.157}}{S u_{w}^{0.3}\left(1+1.09 X_{t t}^{0.039}\right)^{0.4}}\left[\left(\frac{\mu_{w}}{\mu_{o}}\right)^{2}\left(\frac{\nu_{w}}{v_{o}}\right)\right]^{0.084} \text { for } R e_{o}>1250 \\
S u_{w}=\frac{\rho_{w} \sigma D}{\mu_{w}^{2}} \\
X_{t t}=\left(\frac{\mu_{o}}{\mu_{w}}\right)^{0.1}\left(\frac{1-j_{w} / j_{t o t}}{j_{w} / j_{t o t}}\right)^{0.9}\left(\frac{v_{o}}{v_{w}}\right)^{0.5}
\end{gathered}
$$

$263 \mathrm{Kim}$ and Mudawar determined that when $W e^{*}$ was greater than $7 X_{t t}^{0.2}$, the flow regime would be 264 annular, but when $W e^{*}$ was less than $7 X_{t t}^{0.2}$, slug flow would be present. In Figure $9,7 \mathrm{X}_{t t}^{0.2}$ is 265 shown verses $W e^{*}$ in the FEP channel. Flow regimes in which oil was the primary wetting fluid 266 (e.g., stratified, inverted-annular) occur where $W e^{*}$ was greater than $7 X_{t t}^{0.2}$ and $W e^{*}$ was less than $2677 X_{t t}$ when water was the primary wetting fluid (e.g. annular with oil rivulet, intermittent). 


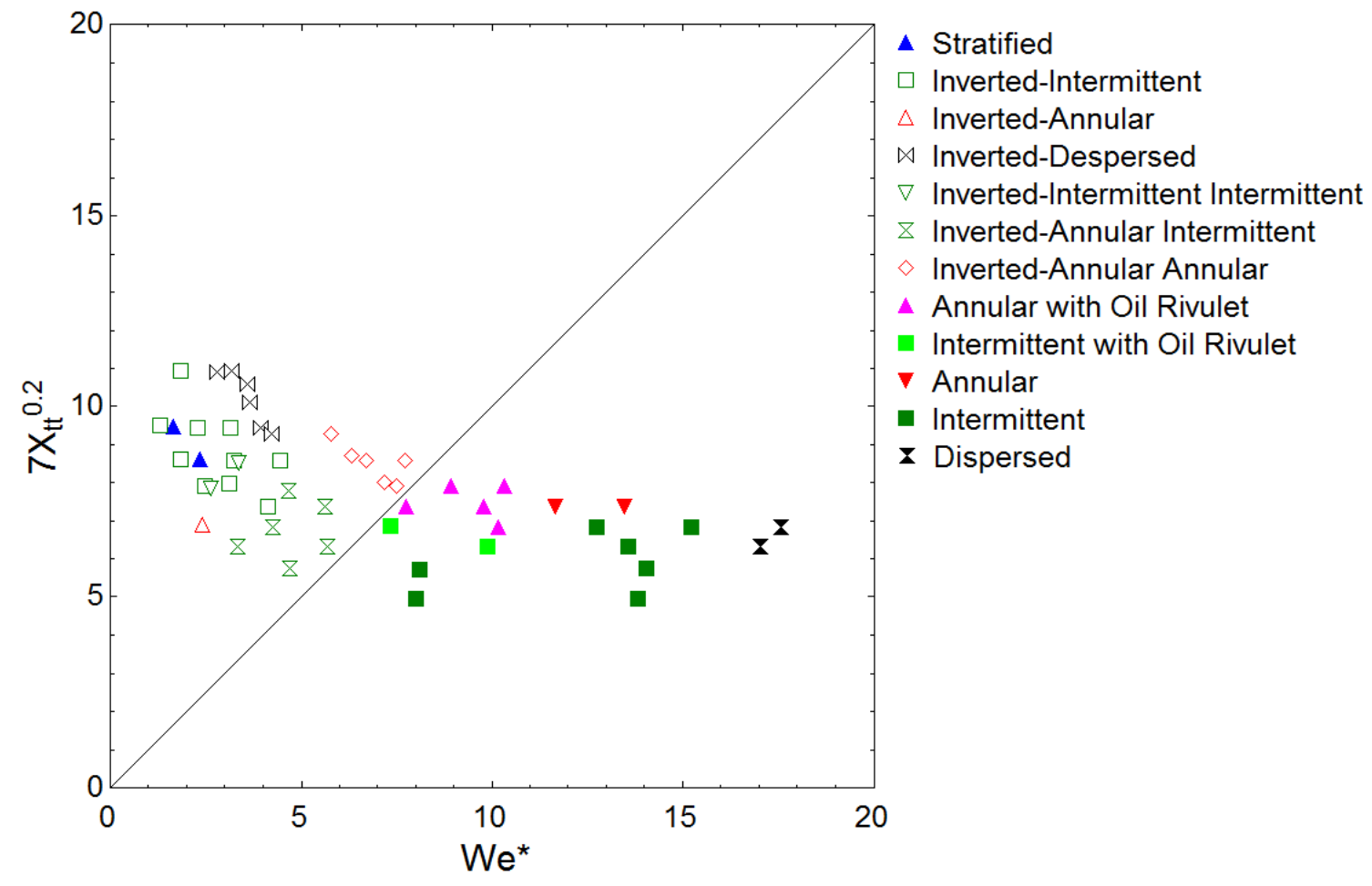

Figure 9: Modified Weber number analysis regarding wall wetting in the FEP tube.

\section{$270 \quad 3.4$ Pressure Drops}

271 In borosilicate glass, measured pressure drops were primarily a function of the water input

272 ratio and oil flow rate. In general, pressure drop followed a parabolic trend as the water input ratio

273 increased for a particular oil flow rate; this corresponded to a higher total superficial velocity. Flow

274 regimes affected pressure drops for the lowest superficial velocities where the stratified flow

275 occurs. In stratified flow, both oil and water are wetting the surface. 


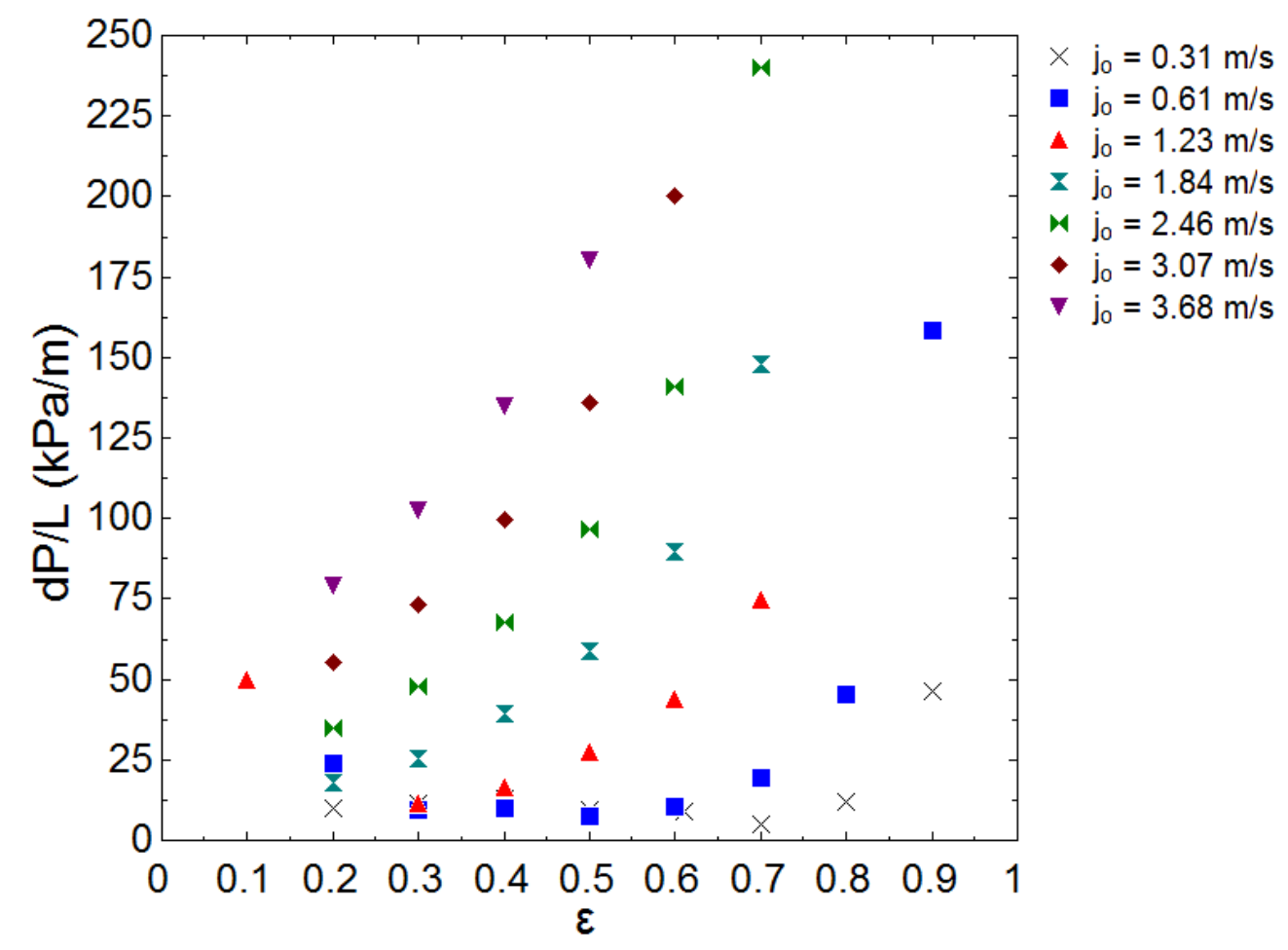

277

Figure 10: Pressure drops in the borosilicate glass tube.

In the FEP mini-channel, the effects of flow regime on the pressure drop were much more

279 significant. A comparison between the pressure drops and flow regimes in glass and FEP is shown

280 in Figure 12 for an oil superficial velocity of $1.8 \mathrm{~m} / \mathrm{s}$. The pressure drop is initial as high as 250

$281 \mathrm{kPa} / \mathrm{m}$ when the flow is inverted and oil wets the wall. As the flow regime transitions from inverted

282 to dual flow, a significant pressure drop occurs as the water annulus is acting as a lubricant for the

283 oil core. This flow regime change typically occurs when $\varepsilon$ is between 0.2 and 0.4 . A smaller

284 pressure decrease then occurs with a dual flow (e.g., inverted-annular intermittent) transitions to a

285 flow with rivulet (e.g., intermittent with oil rivulet). At this point, the pressure drop changes in a

286 way consistent with what has been observed in hydrophilic materials such as borosilicate glass

287 (i.e., increasing with increasing water input ratio). 


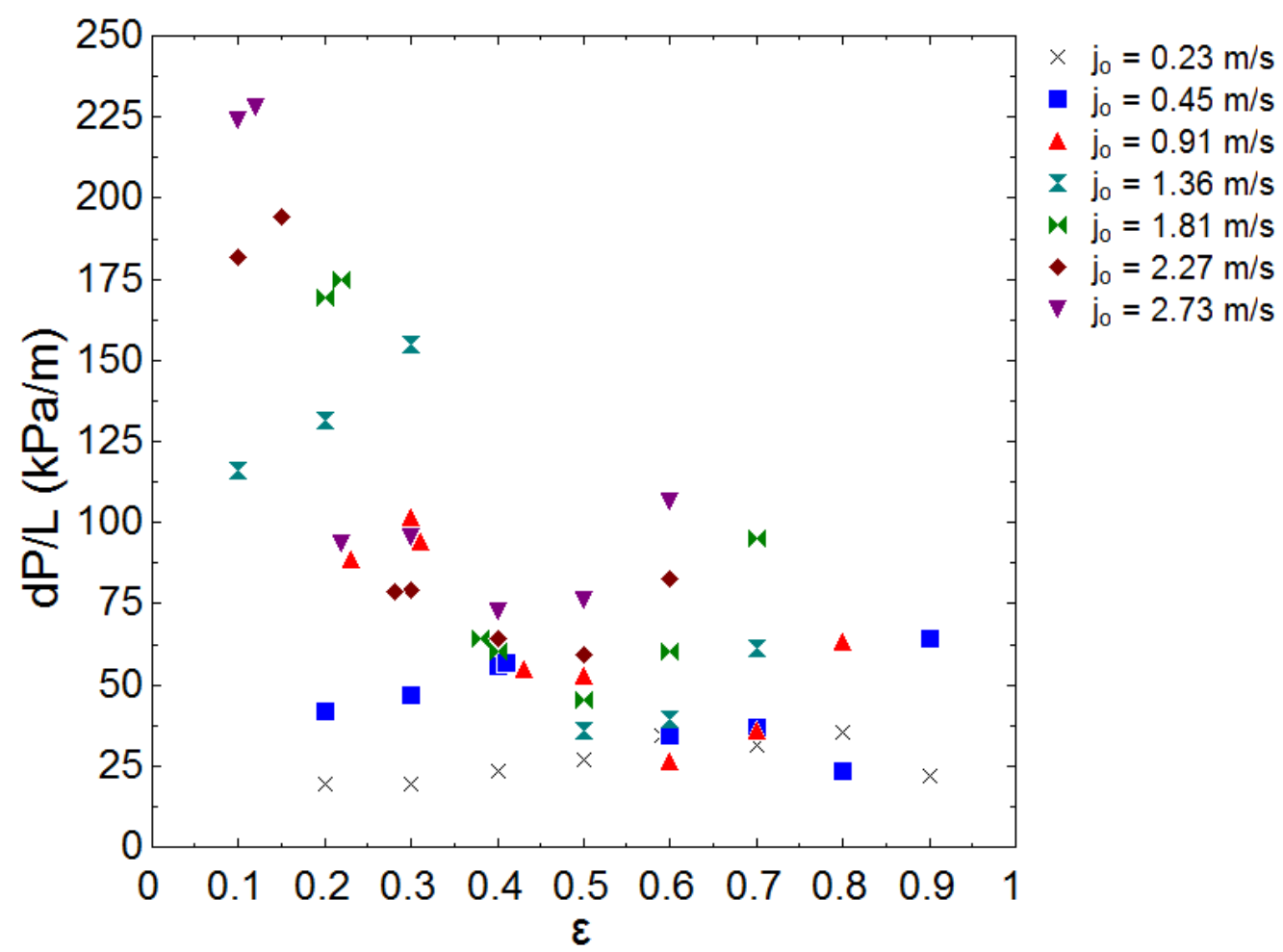

290

Figure 11: Pressure drops in FEP are a strong function of flow regime.

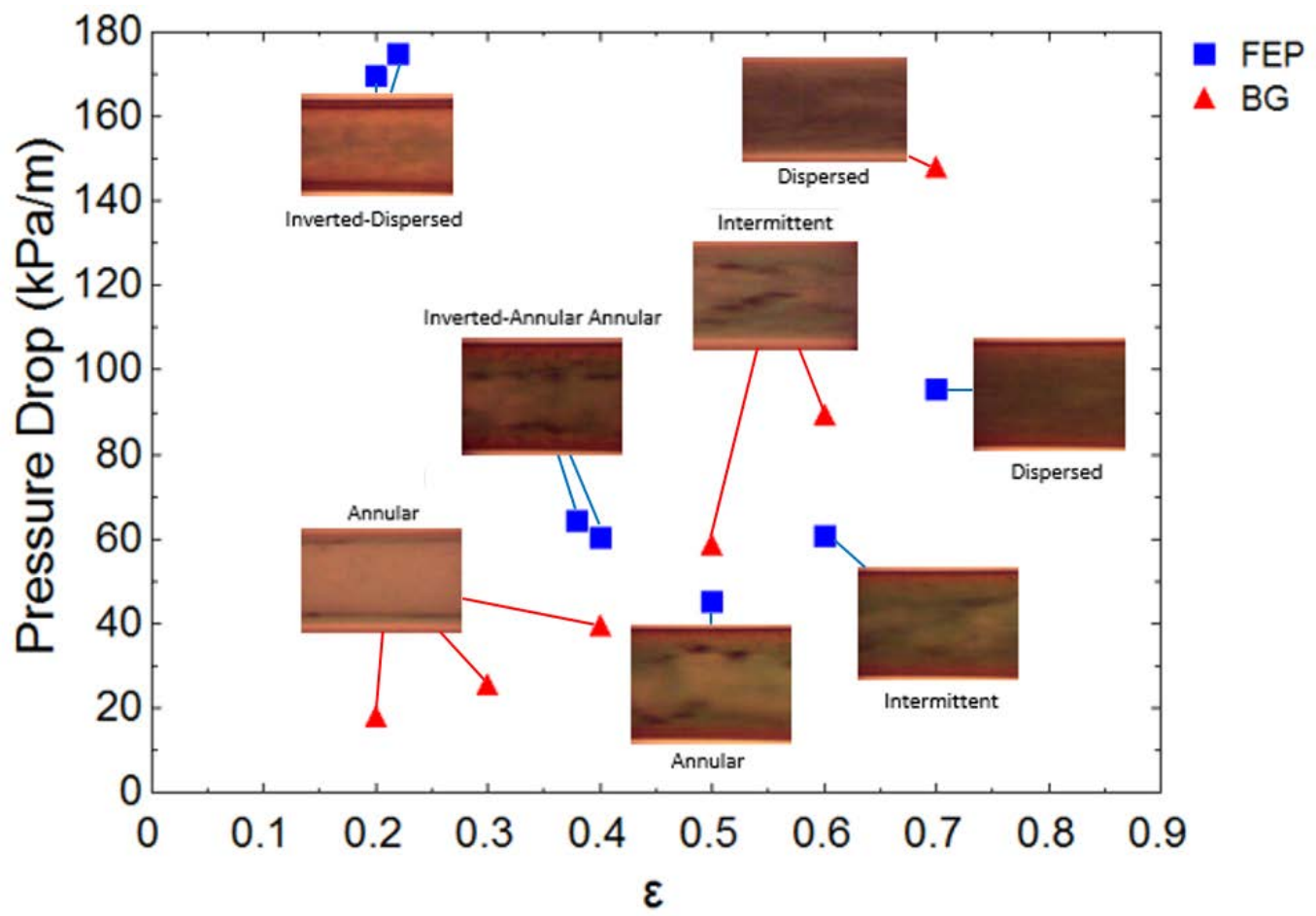

292 Figure 12: Pressure drops and flow regimes at $j_{o}=1.8 \mathrm{~m} / \mathrm{s}$ for both the glass and FEP tubes. 


\section{4. CONCLUSIONS}

294 Flow regimes and pressure drops were observed and measured in hydrophilic glass and 295 hydrophobic FEP channels with Eötvös numbers less than one. Flow regimes and pressure drops 296 varied over a range of oil and water flow rates. The conclusions drawn from the study are as 297 follows: inverted-annular annular flows offer the lowest pressure drop. In inverted-annular flow regimes,

312 oil wets the fluid wall and may be removed from the water using oil-selective membranes. Due to 313 material limitations, this study does not account for the effects of extreme temperature and pressure on fluid properties and flow regimes, as encountered in reservoirs. It is recommended that the 315 effects of these parameters should be examined in future studies. 
316 NOMENCLATURE

\begin{tabular}{|c|c|}
\hline$A$ & Area $\left(\mathrm{m}^{2}\right)$ \\
\hline$D$ & Diameter (m) \\
\hline$E \ddot{~}$ & Eötvös number (-) \\
\hline$R e$ & Reynolds number (-) \\
\hline $\mathrm{Su}$ & Suratman number (-) \\
\hline$W e^{*}$ & Modified Weber number (-) \\
\hline$X$ & Martinelli parameter (-) \\
\hline j & Superficial velocity (m/s) \\
\hline$\dot{m}$ & Mass flow rate (kg/s) \\
\hline$\varepsilon$ & Water input ratio \\
\hline$\mu$ & Dynamic viscosity $(\mathrm{Pa} \cdot \mathrm{s})$ \\
\hline$v$ & Kinematic viscosity $\left(\mathrm{m}^{2} / \mathrm{s}\right)$ \\
\hline$\rho$ & Density $\left(\mathrm{kg} / \mathrm{m}^{3}\right)$ \\
\hline \multicolumn{2}{|c|}{ Subscripts: } \\
\hline tot & Total, both oil and water \\
\hline$O$ & Oil \\
\hline$t t$ & Turbulent-turbulent \\
\hline$w$ & Water \\
\hline
\end{tabular}

\section{ACKNOWLEDGEMENTS}

318 The authors gratefully acknowledge the financial support of OneSubsea, funding from the 319 Department of Mechanical and Nuclear Engineering to fund G.A.R., and the assistance of Jarrod 320 Booth in collecting the data. 
321

322

323

324

325

326

327

328

329

330

331

332

333

334

335

336

337

338

339

340

341 342 411-432.

\section{References} pp. 59-72.

[1] Bannwart, A. C., 2001, "Modeling aspects of oil-water core-annular flows," Journal of Petroleum Science and Engineering, 32(2), pp. 127-143.

[2] Cai, J., Li, C., Tang, X., Ayello, F., Richter, S., and Nesic, S., 2012, "Experimental study of water wetting in oil-water two phase flow-Horizontal flow of model oil," Chemical Engineering Science, 73, pp. 334-344.

[3] Bultongez, K. K., and Derby, M. M., 2017, "Investigation of oil-water flow regimes and pressure drops in mini-channels," International Journal of Multiphase Flow, 96, pp. 101-112. [4] Andreini, P., De Greeff, P., Galbiati, L., Kuhlwetter, A., and Sotgia, G., "Oil-water flow in small diameter tubes," Proc. ICHMT DIGITAL LIBRARY ONLINE, Begel House Inc.

[5] Kandlikar, S. G., and Grande, W. J., "Evolution of microchannel flow passages: thermohydraulic performance and fabrication technology," Proc. ASME 2002 International Mechanical Engineering Congress and Exposition, American Society of Mechanical Engineers,

[6] Brauner, N., and Moalem Maron, D., "‘Classification of Liquid-Liquid Two-Phase Flow Systems and The Prediction of Flow Pattern Maps," Proc. 2nd International Symposium on TwoPhase Flow Modeling and Experimentation-ISTP, pp. 747-754.

[7] Taitel, Y., and Dukler, A., 1976, "A model for predicting flow regime transitions in horizontal and near horizontal gas-liquid flow," AIChE Journal, 22(1), pp. 47-55.

[8] Xu, J. L., Cheng, P., and Zhao, T. S., 1999, "Gas-liquid two-phase flow regimes in rectangular channels with mini/micro gaps," International Journal of Multiphase Flow, 25, pp. 
343 [9] Garimella, S., 2004, "Condensation Flow Mechanisms in Microchannels: Basis for Pressure 344 Drop and Heat Transfer Models," Heat Transfer Engineering, 25(3), pp. 104-116.

345 [10] Coleman, J. W., and Garimella, S., 2003, "Two-phase flow regimes in round, square and 346 rectangular tubes during condensation of refrigerant R134a," International Journal of

347 Refrigeration, 26(117-128).

348 [11] Kandlikar, S. G., 2002, "Two-phase flow patterns, pressure drop, and heat transfer during 349 boiling in minichannel flow passages of compact evaporators," Heat Transfer Engineering, $350 \quad$ 23(1), pp. 5-23.

351 [12] Revellin, R., and Thome, J., 2007, "A new type of diabatic flow pattern map for boiling heat 352 transfer in microchannels," Journal of Micromechanics and Microengineering, 17(4), p. 788.

353 [13] Brauner, N., and Ullmann, A., 2002, "Modeling of phase inversion phenomenon in two354 phase pipe flows," International Journal of Multiphase Flow, 28(7), pp. 1177-1204.

355 [14] Beretta, A., Ferrari, P., Galbiati, L., and Andreini, P., 1997, "Horizontal oil-water flow in 356 small diameter tubes. Flow patterns," International communications in heat and mass transfer, 357 24(2), pp. 223-229.

358 [15] Bultongez, K. K., and Derby, M. M., "Oil-water flow visualization and flow regimes in a $3593.7 \mathrm{~mm}$ mini-channel," Proc. Proceedings of the 14th International Conference on Nanochannels, 360 Microchannels, and Minichannels (ICNMM).

361 [16] Grassi, B., Strazza, D., and Poesio, P., 2008, "Experimental validation of theoretical models 362 in two-phase high-viscosity ratio liquid-liquid flows in horizontal and slightly inclined pipes," 363 International Journal of Multiphase Flow, 34(10), pp. 950-965. 
364 [17] Sotgia, G., Tartarini, P., and Stalio, E., 2008, "Experimental analysis of flow regimes and 365 pressure drop reduction in oil-water mixtures," International Journal of Multiphase Flow, 366 34(12), pp. 1161-1174.

367 [18] Lovick, J., and Angeli, P., 2004, "Experimental studies on the dual continuous flow pattern 368 in oil-water flows," International Journal of Multiphase Flow, 30(2), pp. 139-157.

369 [19] da Silva, R. C. R., Mohamed, R. S., and Bannwart, A. C., 2006, "Wettability alteration of 370 internal surfaces of pipelines for use in the transportation of heavy oil via core-flow," Journal of 371 Petroleum Science and Engineering, 51(1), pp. 17-25.

372 [20] Arney, M. S., Ribeiro, G. S., Guevara, E., Bai, R., and Joseph, D. D., 1996, "Cement-lined 373 pipes for water lubricated transport of heavy oil," International Journal of Multiphase Flow, $374 \quad 22(2)$, pp. 207-221.

375 [21] Ismail, A. S. I., Ismail, I., Zoveidavianpoor, M., Mohsin, R., Piroozian, A., Misnan, M. S., 376 and Sariman, M. Z., 2015, "Experimental investigation of oil-water two-phase flow in horizontal 377 pipes: Pressure losses, liquid holdup and flow patterns," Journal of Petroleum Science and 378 Engineering, 127, pp. 409-420.

379 [22] Wang, W., Gong, J., and Angeli, P., 2011, "Investigation on heavy crude-water two phase 380 flow and related flow characteristics," International Journal of Multiphase Flow, 37(9), pp. 11563811164.

382 [23] Xu, X.-X., 2007, "Study on oil-water two-phase flow in horizontal pipelines," Journal of 383 Petroleum Science and Engineering, 59(1), pp. 43-58.

384 [24] Li, C., Tang, X., Ayello, F., Cai, J., Nesic, S., Cruz, C. I. T., and Al-Khamis, J. N., 2006, 385 "Experimental study on water wetting and CO2 corrosion in oil-water two-phase flow," NACE 386 Corrosion, 6. 
[25] Oglesby, K. D., 1979, An experimental study on the effects of oil viscosity, mixture velocity and water fraction on horizontal oil-water flow, University of Tulsa, Fluid Flow Projects. [26] Tsaoulidis, D., Dore, V., Angeli, P., Plechkova, N. V., and Seddon, K. R., 2013, "Flow patterns and pressure drop of ionic liquid-water two-phase flows in microchannels," International Journal of Multiphase Flow, 54, pp. 1-10.

[27] Brauner, N., 2003, "Liquid-liquid two-phase flow systems," Modelling and Experimentation in Two-Phase Flow, Springer, pp. 221-279.

[28] Salim, A., Fourar, M., Pironon, J., and Sausse, J., 2008, "Oil-water two-phase flow in microchannels: Flow patterns and pressure drop measurements," The Canadian Journal of Chemical Engineering, 86(6), pp. 978-988.

[29] Foroughi, H., and Kawaji, M., 2011, "Viscous oil-water flows in a microchannel initially saturated with oil: flow patterns and pressure drop characteristics," International Journal of Multiphase Flow, 37(9), pp. 1147-1155.

[30] Yun, W., Ross, C. M., Roman, S., and Kovscek, A. R., 2017, "Creation of a dual-porosity and dual-depth micromodel for the study of multiphase flow in complex porous media," Lab on a Chip, 17(8), pp. 1462-1474.

[31] Xu, K., Liang, T., Zhu, P., Qi, P., Lu, J., Huh, C., and Balhoff, M., 2017, "A 2.5-D glass micromodel for investigation of multi-phase flow in porous media," Lab on a Chip, 17(4), pp. 640-646.

[32] Schmitz, E. A., 2018, "Impacts of industrial water composition on Salicornia in a hydroponic system," M.S., Kansas State University, Manhattan, KS.

[33] Rulison, C., 2018, "Augustine Report April 11 2018," Augustine Scientific.

[34] Brauner, 2004, "Liquid-Liquid two-phase flow systems," CISM Center, Udine, Italy. 
410 [35] De, B., Mandal, T., and Das, G., 2010, "The rivulet flow pattern during oil-water horizontal

411 flow through a 12 mm pipe," Experimental Thermal and Fluid Science, 34(5), pp. 625-632.

412 [36] Jovanović, J., Zhou, W., Rebrov, E. V., Nijhuis, T., Hessel, V., and Schouten, J. C., 2011,

413 "Liquid-liquid slug flow: hydrodynamics and pressure drop," Chemical Engineering Science, 414 66(1), pp. 42-54.

415 [37] Charles, M. E., Govier, G. t., and Hodgson, G., 1961, "The horizontal pipeline flow of equal 416 density oil-water mixtures," the Canadian Journal of Chemical engineering, 39(1), pp. 27-36.

417 [38] Kim, S.-M., and Mudawar, I., 2013, "Universal approach to predicting saturated flow 418 boiling heat transfer in mini/micro-channels-Part II. Two-phase heat transfer coefficient," 419 International Journal of Heat and Mass Transfer, 64, pp. 1239-1256.

420 [39] Kim, S.-M., and Mudawar, I., 2012, "Flow condensation in parallel micro-channels-Part 2:

421 Heat transfer results and correlation technique," International Journal of Heat and Mass Transfer, 422 55(4), pp. 984-994.

423

424 (C) 2018. This manuscript version is made available under the CC-BY-NC-ND 4.0 license 425 http://creativecommons.org/licenses/by-nc-nd/4.0/ 